\title{
A national strategy for the management of chronic obstructive pulmonary disease (COPD) in England: aiming to improve the quality of care for patients
}

\author{
*Kevin Gruffydd-Jones ${ }^{\mathrm{a}, \mathrm{b}}$ \\ a Honorary lecturer, Universities of Bath and Aberdeen, UK \\ b General Practitioner, Box Surgery, Wiltshire, UK
}

Received 29th October 2008; revised version received 10th November 2008; final revisions received 12th November; accepted 14th November 2008

\begin{abstract}
This article examines the rationale behind the development of the National Clinical Strategy for Chronic Obstructive Pulmonary Disease (COPD) in England which will be launched in 2009. It focuses on the burden which COPD places on the healthcare service and the effect it has on patients, and highlights the important steps in the development of the Clinical Strategy. The general recommendations which are likely to be contained within the Clinical Strategy are discussed, as well as the possible implications for primary care.

(c) 2008 General Practice Airways Group. All rights reserved.

K Gruffydd-Jones. Prim Care Resp J 2008; 17(Suppl 1): S1-S8.

doi:10.3132/pcrj.2008.00071
\end{abstract}

Keyw ords: COPD, UK, Clinical Strategy, rationale, diagnosis, management, treatment

\section{Contents}

Introduction

Rationale for the COPD Clinical Strategy

The burden of the disease.

The effect on the individual - the "Unleash the life within" survey...

Development of the Clinical Strategy.....

The Chief Medical Officer's Annual Report, 2005

The Healthcare Commission Report, 2006

Aims and methodology

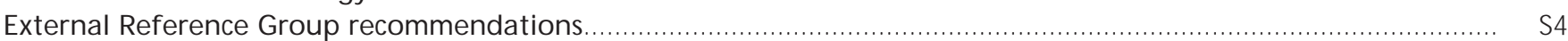

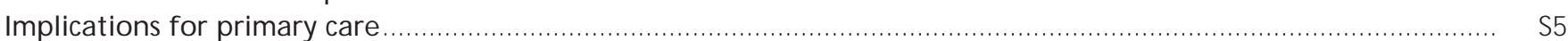

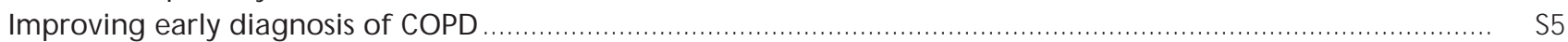

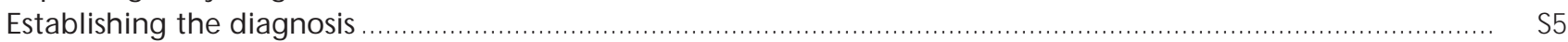

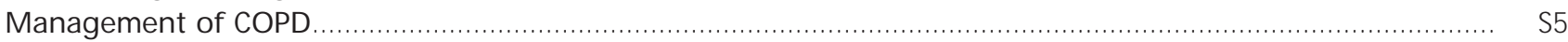

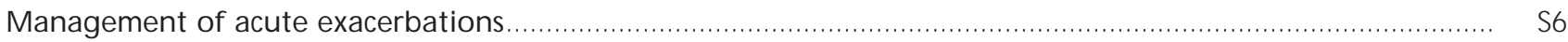

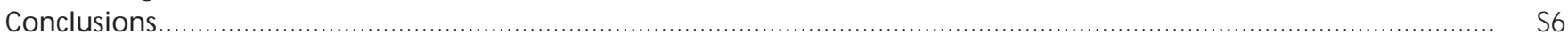

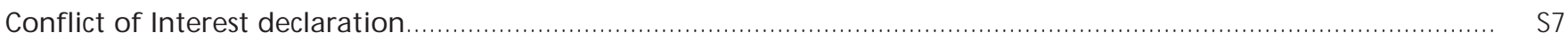

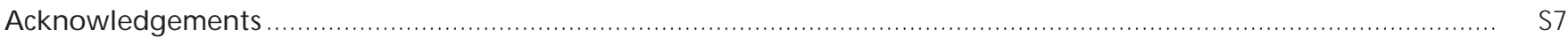

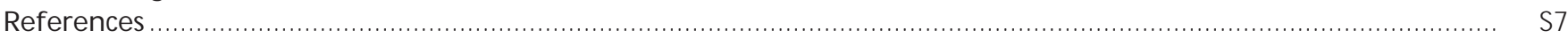

\footnotetext{
* Correspondence: Box surgery, Wiltshire, SN13 8NA, UK.

Tel: +44 (0)1225 742361 Fax: +44 (0)1225 742646 E-mail: Kevin.Gruffydd-Jones@gp-J83013.nhs.uk
} 


\section{Introduction}

This PCRJ supplement article, based on the National Clinical Strategy for Chronic Obstructive Pulmonary Disease (COPD) in England which will be launched in 2009, discusses various aspects of COPD management. In particular, it focuses on;

- The rationale for the Clinical Strategy (formerly known as the National Service Framework [NSF]) - in particular, the burden of the disease and the impact on patients as demonstrated by various patient surveys

- The development of the Clinical Strategy

- The general recommendations on which the Clinical Strategy is based

- The possible implications for primary care.

\section{Rationale for the COPD Clinical Strategy}

The burden of the disease

COPD exerts a huge burden on the health economy and on the individual patient. It is the sixth leading cause of death in the world and is expected to become the third leading cause of death by $2020 .{ }^{1}$ In the UK, COPD leads to more than 27,000 deaths per year, ${ }^{2}$ approximately $16 \%$ of patients admitted to hospital for COPD will die within three months, and almost a quarter will die within a year after admission. ${ }^{3}$ There are currently an estimated 3 million people suffering from COPD in the UK, ${ }^{4}$ and only about 900,000 of these patients have been diagnosed and are receiving treatment. Therefore, over 2 million patients are undiagnosed and unaware of a disease which could eventually kill them after years of substantial disability. The age-related prevalence of diagnosed COPD is outlined in Table 1 .

COPD also places a heavy burden on the healthcare service. The estimated number of patients suffering from COPD equates to about 1.4 million general practitioner (GP) consultations per year. This is up to four times the number of consultations for angina. Even though only a small proportion of COPD patients are admitted to hospital each year, COPD is the second largest cause of emergency admissions in the UK at 130,000 admissions per year. The inpatient care for COPD accounts for almost half the NHS expenditure on the disease and it remains one of the most costly inpatient conditions in the NHS. ${ }^{5}$ A breakdown of the costs of COPD in 2000/2001 is outlined in Table 2. The National Institute for Health and Clinical Excellence (NICE) estimates the direct cost of COPD at more than $f 491$ million per year and $f 982$ million per year when including indirect costs. ${ }^{6}$

COPD also has an economic impact in addition to its cost to the NHS. In 1994-5 it was estimated that 21.9 million working days were lost due to COPD. ${ }^{6}$

The effect on the individual - the "Unleash the life within" survey

Patients with COPD experience poor quality of life with
Table 1: Estimated prevalence of COPD*6

\begin{tabular}{llll} 
Age & Men & Women & Total \\
\hline $44-65$ & 143,700 & 107,100 & 250,800 \\
\hline$>65$ & 322,000 & 310,500 & 632,500 \\
\hline & & 883,300 \\
\hline *In England and Wales using GPRD prevalence rates and 1999 \\
population estimates
\end{tabular}

\section{Table 2: The cost of COPD in 2000/20016}

The estimated cost to the NHS per annum of caring for a person with COPD was:

$$
\begin{array}{ll}
\text { - } & \text { Mild COPD - } £ 149.68 \\
\text { - } & \text { Moderate COPD - } £ 307.74 \\
\text { - } & \text { Severe COPD - } £ 1,307.10
\end{array}
$$$$
15
$$

impaired emotional, social and physical functioning. They may also lsuffer from psychological disorders such as depression, which may go unnoticed.?

There are various surveys that have highlighted the substantial effect of COPD on the lives of sufferers. One of the most recent, "Unleash the life within", was commissioned by AstraZeneca to assess aspects of COPD management and the need for more patient-focussed care. ${ }^{8}$ The survey was conducted by a multi-disciplinary team in order to focus attention on the goals of treatment which matter most to COPD patients, in the hope that effective strategies could be devised to meet both patient and treatment goals. Questionnaires were distributed to 83 pharmacies in those UK areas identified as having a particularly high rate of COPD admissions in the "Invisible Lives" Survey commissioned by the British Lung Foundation in $2007.9 .10 \mathrm{~A}$ total of 326 people with COPD, aged 46 and over, completed the questionnaire provided by pharmacists on collection of their COPD medication. The objectives of the survey were:

- To understand how COPD affects patients' everyday lives and which aspects of their lives are most affected

- To elicit the extent to which education is provided for patients about their inhalers

- To ascertain any particular difficulties patients have in undertaking activities of daily living when they have unstable symptoms

- To understand to what extent COPD patients are satisfied with their treatment ${ }^{8}$ 


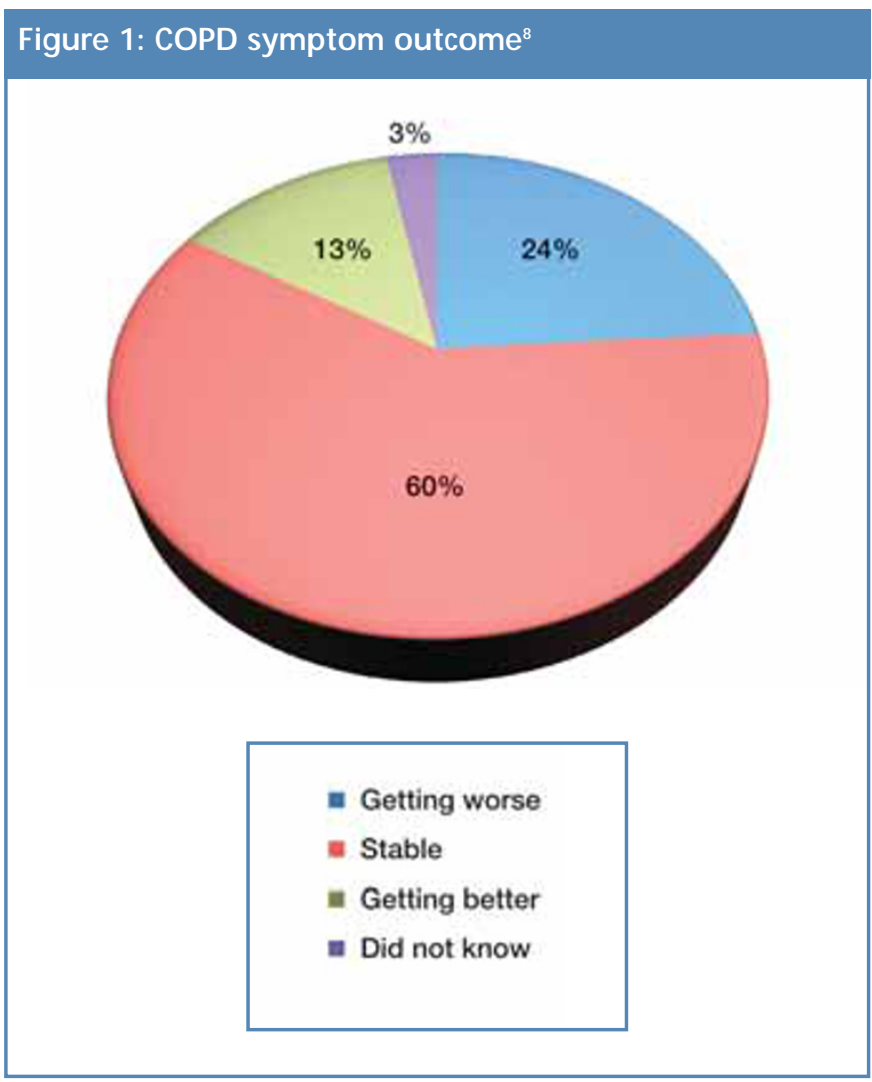

The results showed that nearly a quarter of patients thought their symptoms were worsening and one in five felt that their COPD was not well controlled (Figures 1 and 2\%). Nearly a quarter of respondents said that the worst effect on their daily living was not being able to take part in hobbies or play with their grandchildren. Not being able to walk a short distance also had a negative impact. Chronic tiredness, depression and frustration also made their lives less enjoyable. ${ }^{8}$

The large majority $(85 \%)$ of patients were reviewed by either a doctor or nurse during the previous 12 months and most clinicians enquired about clinical symptoms. However, only one in three patients were asked about the effect of the disease on their everyday life, and more than half were not offered supportive therapies such as home visits or pulmonary rehabilitation. One in three patients needed hospital treatment during the previous year and the majority of patients who were offered supportive therapies had been admitted to hospital for COPD twice or more in the previous year. Some patients commented that the stay in hospital had a demoralising impact on them. ${ }^{8}$

The "Unleash the life within" survey illustrates the significant disability and loss of independence experienced by patients with COPD, and the impact this has on their everyday lives. The results reflect the views of symptomatic patients in areas with a high prevalence of COPD, and obviously these
Figure 2: COPD symptom control ${ }^{8}$
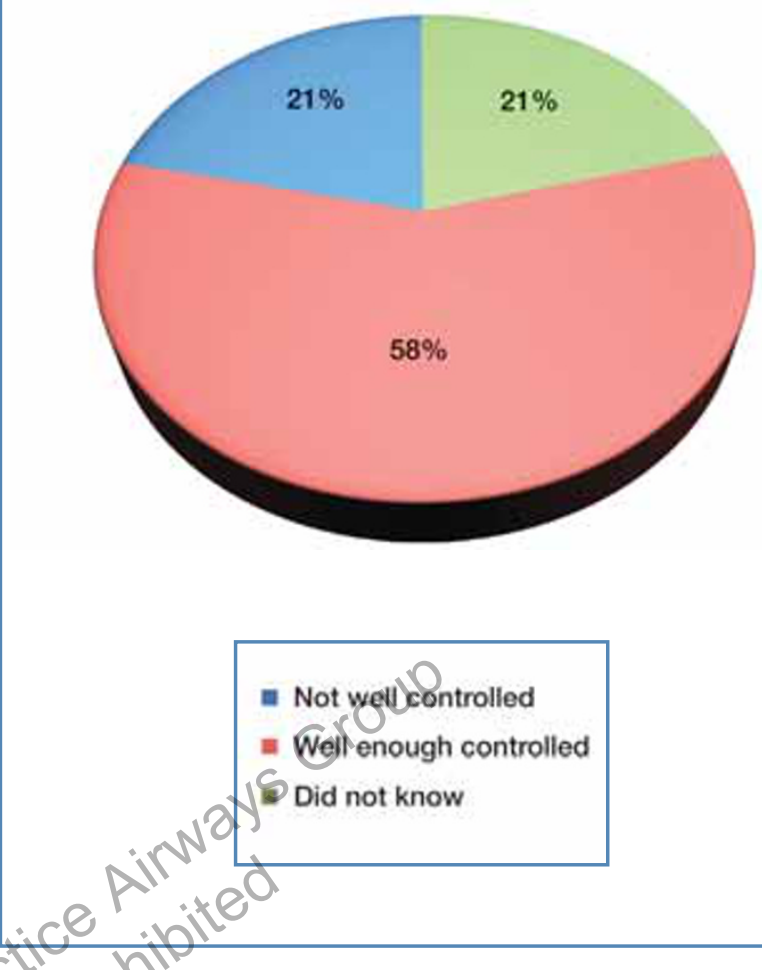

views cannot be generalised to all COPD patients. Nevertheless, they offer a useful insight into the way that COPD affects a group of symptomatic patients from different areas of the UK.

\section{Development of the Clinical Strategy}

The Chief Medical Officer's Annual Report, 20057

In 2005, the Chief M edical Officer, Sir Liam Donaldson, drew attention to the impact of COPD - and the need for improved care - in his annual report. The report highlighted concerns regarding the diagnosis of COPD and its treatment. However, it also suggested measures that could improve care and patients' quality of life. These include:

- The use of the Expert Patient Programme, which helps patients take control of their own care

- Improving management in hospitals, through increasing the number of doctors and nurses training in respiratory specialties

- Highlighting to healthcare professionals the benefits of non-invasive ventilation for exacerbations as well as pulmonary rehabilitation

- Improving access to pulmonary rehabilitation

- Increased training in the use of spirometry

Sir Liam's final recommendation was that a National Service Framework for COPD (now called a Clinical Strategy) should be formulated. ${ }^{7}$ 
The Healthcare Commission report, $2006^{5}$

In 2006, a report by the Healthcare Commission also highlighted concerns in relation to provision of care for COPD patients. They included:

- Under-diagnosis and misdiagnosis of COPD

- Lack of appropriate structured care

- Lack of access to, and participation in, pulmonary rehabilitation

- Rising hospital admission rates

- Poor prognosis

- Poor patient quality of life

Awareness of COPD among healthcare professionals and the public was also felt to be lacking. ${ }^{5}$ In 2007, the British Lung Foundation carried out a survey which showed that $89 \%$ of people in the UK and $85 \%$ of smokers had not heard of the term "COPD" . ${ }^{10}$ The report also highlighted patients' concerns about the lack of consistency in the diagnostic methods used, and the lack of clear communication about the diagnosis by health professionals. ${ }^{5}$

The report stated that it is essential that clear and consistent information is provided to patients and carers concerning the diagnosis and that it is delivered in a manner sensitive to the deep anxiety the diagnosis will cause. ${ }^{5}$ It also highlighted that objectives for the care of patients with COPD were "more likely to be achieved if care is systematic, proactive and planned rather than ad hoc, reactive and unstructured." As a national recommendation it was concluded that better measures for performance and outcomes were needed. ${ }^{5}$

\section{Aims and methodology}

In early 2009, the Department of Health will complete the Clinical Strategy for COPD (Figure 3). The aims of the strategy are to:

- Improve the quality of, and access to, COPD services

- Reduce inequalities (e.g. between the north and south of England)

- Reduce healthcare utilisation costs

The methodology of the Clinical Strategy is outlined in Figure 3 , and the time scale is outlined in Figure $4 . .^{11,12}$

\section{External Reference Group recommendations}

An External Reference Group (ERG) was established in 2006. This group included health professionals, health service managers, service users and carers, who were asked to advise on the development of the Clinical Strategy. The members of the ERG systematically reviewed the evidence on the management and treatment of COPD, and they have developed national aims for the prevention, identification and management of COPD and its major complications. The ERG recommendations will now be reviewed in order to develop the published Clinical Strategy.

The ERG recommendations for the Clinical Strategy include: working to establish the value of a lung health check together with a strategy to identify opportunistically undiagnosed or misdiagnosed cases

Improving diagnostic accuracy, including linking with the detection of lung cancer in patients with moderate/severe COPD

\section{Figure 3. Clinical Strategy methodology ${ }^{12}$ [reproduced with permission]}

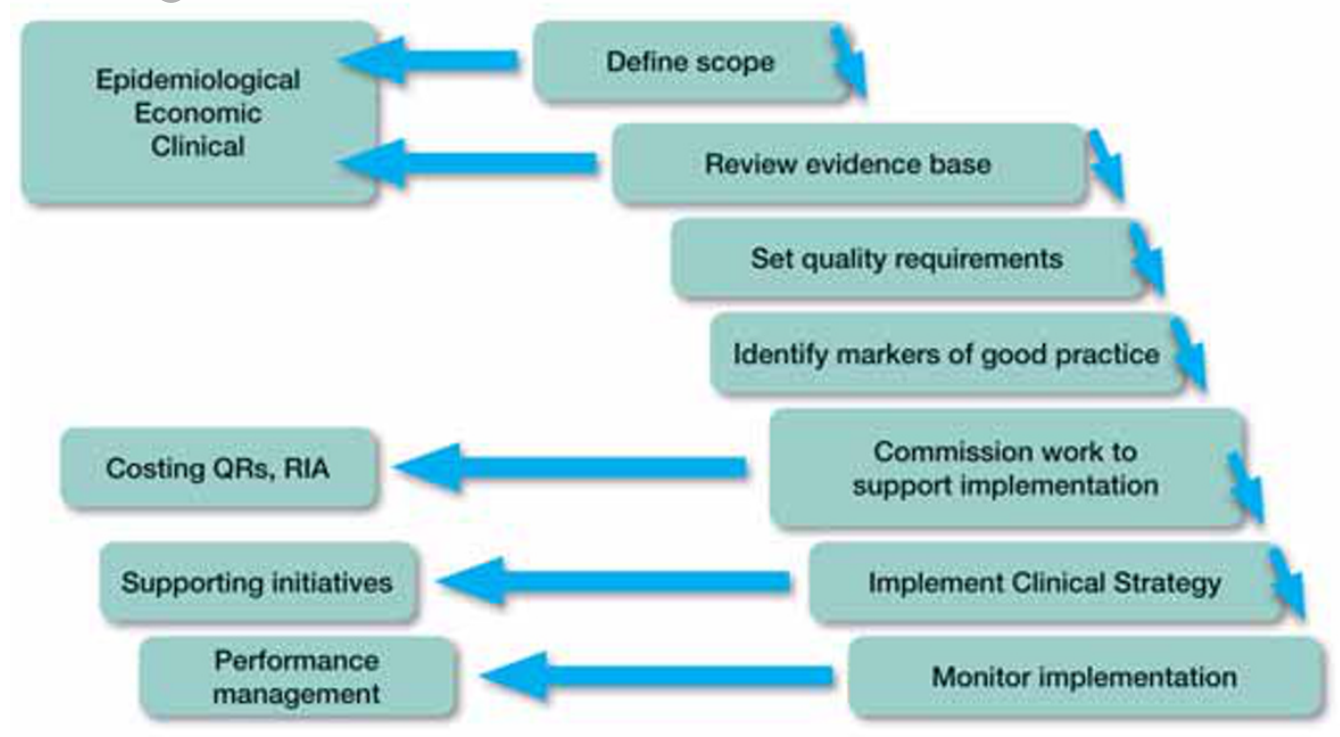

Adapted from the Department of Health website (Clinical Strategy due 2009) 
Figure 4: Clinical Strategy time scale ${ }^{12}$ [reproduced with permission]

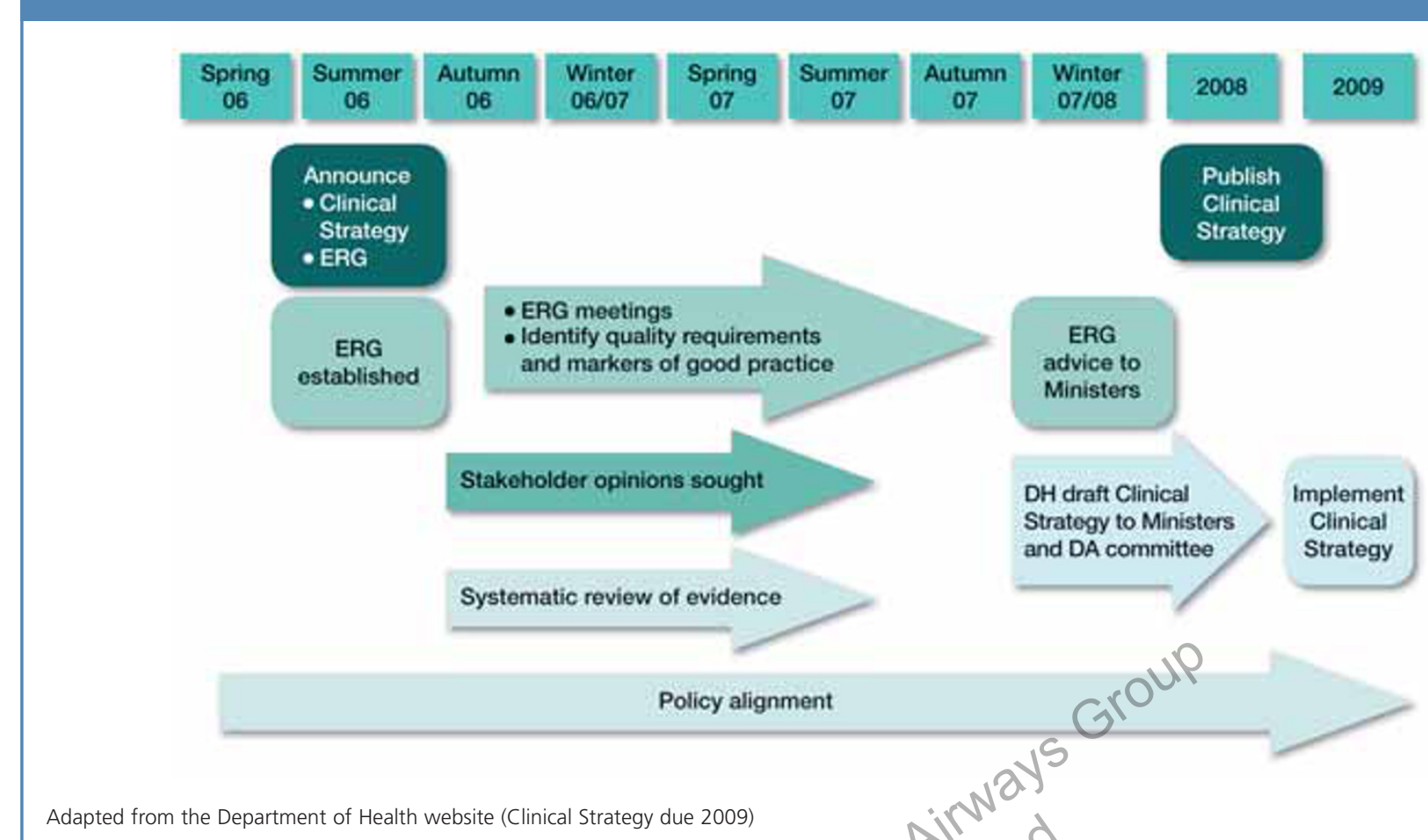

Adapted from the Department of Health website (Clinical Strategy due 2009)

- The development of a chronic care model that leads to more pro-active management of COPD - with systematic reviews depending on the severity of the condition

- The establishment of managed clinical networks to effect co-ordinated change and consistent high quality care within the different areas of the NHS and social care delivering care to the individual patient

- Optimising care during inpatient episodes to improve clinical outcomes and decrease recurrent hospitalisation

- Using innovative technology to deliver and monitor care

- Improved support for patients and carers ${ }^{11}$

\section{Implications for primary care}

Improving early diagnosis of COPD

A lack of awareness and understanding of COPD among the public, as well as a lack of confident diagnosis, has contributed to its under-diagnosis, with only $47 \%$ of patients with one or more symptoms of COPD consulting their GP. ${ }^{5}$ There are several ways to increase the diagnosis of COPD; one of these may be case finding.

The value of case finding patients with COPD is still a matter of debate. Case finding of patients with COPD using spirometry can lead to increased rates of smoking cessation, ${ }^{13}$ although it has been argued that this benefit does not apply to patients with mild disease. ${ }^{14}$ It is likely that the Clinical Strategy will not recommend general population screening with spirometry but case finding of high risk patients, possibly also with the use of questionnaires..$^{15}$ This approach may be more time-efficient if it is combined with screening for other conditions such as hypertension, diabetes and hypercholesterolaemia. ${ }^{16}$

\section{Establishing the diagnosis}

Diagnosis of symptomatic COPD depends on the traditional tools of:

- An accurate history

- Examination

- Investigations

These will focus on the positive elements of COPD (e.g. persistent breathlessness, cough) while excluding features of other causes of the presenting symptoms (e.g. cardiac and other lung pathology). A key element of this process is the use of spirometry to identify airflow obstruction. The Clinical Strategy is likely to address the concerns around the varying quality of spirometry procedures and interpretation.

Management of COPD

The National Institute for Clinical Excellence (NICE) Guidelines in the UK ${ }^{17}$ and the Global Initiative for Chronic Lung Disease

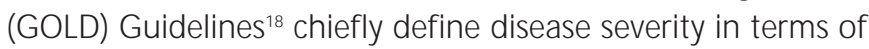
the degree of airflow limitation (see Table 3 for NICE definition of severity) as measured by the forced expiratory volume in 1 second $\left(\mathrm{FEV}_{1}\right)$ expressed as $\%$ predicted. However, whilst the measurement of $\mathrm{FEV}_{1}$ is vital for the diagnosis of COPD and is useful for tracking the progress of the disease over time: 
Table 3: NICE grading of airflow obstruction severity ${ }^{17}$

\begin{tabular}{ll} 
Severity & FEV $_{1} \%$ predicted \\
\hline Mild & $50-80$ \\
\hline Moderate & $30-49$ \\
\hline Severe & $<30$ \\
\hline
\end{tabular}

- $\mathrm{FEV}_{1}$ does not correlate well with quality of life in patients with $\mathrm{COPD}^{6,19}$

- The level of $\mathrm{FEV}_{1}$ is not a good guide to management In fact, the degree of airflow obstruction in COPD is only one facet of a multi-system disease which can lead to muscle wasting, functional limitations and depression, and one which has appreciable co-morbidities (e.g. osteoporosis, cardiac failure).

Multi-dimensional indices of severity like the BODE index $(\text { Table } 4)^{20}$ or DOSE index (Table 5$)^{21}$ may be more useful as a measure of disease severity. A patient-centred approach to management, such as that suggested by the General Practice Airways Group (Figure 5 ) $^{22}$ may therefore be a more practical guide to management, especially in primary care.

It is likely that the Clinical Strategy will recommend a chronic disease model of care which recognises:

- The importance of the multi-system nature of the disease including managing co-morbidities

- The importance of psychosocial factors (in the management of the patients and their carers

The Clinical Strategy may also highlight the importance of combining effective pharmacological treatment with nonpharmacological interventions - for example, the use of patient action plans and pulmonary rehabilitation, together with combination inhaled corticosteroid/ inhaled long acting beta $_{2}$-agonist inhalers in order to help reduce the impact of COPD exacerbations.

\section{Management of acute exacerbations}

There is a need to improve the management of exacerbations in order to reduce hospital admission and readmission rates. The ERG emphasises improving in-patient care, but there is also a need to improve management at the primary/secondary care interface by:

- Improving management in the community to reduce admission to hospital (e.g. by "hospital at home" schemes)

- Improving management following discharge from hospital in order to reduce re-admission

The aim is that the development of local clinical networks will improve this integrated approach to care.
Table 4: Variables and point values used to calculate BODE index ${ }^{20}$

\begin{tabular}{lcccc} 
Variable & \multicolumn{4}{c}{ Points on BODE index } \\
\hline & 0 & 1 & 2 & 3 \\
\hline FEV 1 (\% of predicted)* $^{2}$ & $\geq 65$ & $50-64$ & $36-49$ & $\leq 35$ \\
\hline Distance walked in 6 min $(\mathrm{m})$ & $\geq 350$ & $250-349$ & $150-249$ & $\leq 149$ \\
\hline M M RC dyspnoea scale** & $0-1$ & 2 & 3 & 4 \\
\hline Body-mass indext & $>21$ & $\leq 21$ & & \\
\hline
\end{tabular}

The cutoff values for the assignment of points are shown for each variable. The total possible values range from 0 to $10 . \mathrm{FEV}_{1}$ denotes forced expiratory volume in one second.

* The FEVs categories are based on stages identified by the American Thoracic Society.

** Scores on the modified Medical Research Council (MMRC) dyspnea scale range from 0 to 4 , with a score of 4 indicating that the patient is too breathless to leave the house or becomes breathless when dressing or undressing.

† The values of body-mass index were 0 or 1 because of the inflection point in the inverse relation between survival and body-mass index at a value of 21 .

Table 5 : The DOSE scoring system ${ }^{23}$

\begin{tabular}{lcccc}
\hline DOSE score & 0 & 1 & 2 & 3 \\
\hline M RC dyspnoea scale & $1-2$ & 3 & 4 & 5 \\
\hline FEV $_{1}$ (\% predicted) & $>50$ & $30-49$ & 30 & \\
\hline Exacerbations per year & $0-1$ & $2-3$ & $>3$ & \\
\hline Smoking status & $\begin{array}{c}\text { Non- } \\
\text { smoker }\end{array}$ & $\begin{array}{l}\text { Current } \\
\text { smoker }\end{array}$ & & \\
\hline
\end{tabular}

\section{Conclusions}

The advent of a Clinical Strategy for COPD in England is to be welcomed. It should raise the profile of a previously neglected condition among a wider lay and professional audience, and should improve access to care for all patients with COPD, thereby reducing health inequalities. The Clinical Strategy recognises that COPD is not just a disease of the lungs, but is rather a multi-system disease which can have profound psychosocial effects on patients and their carers. In recognition of this the Clinical Strategy is likely to advocate an holistic approach to management which has its roots firmly based in primary care. The successful implementation of the Clinical Strategy will require an integrated approach, with primary and secondary care clinicians working alongside patients and health service managers. 
Figure 5: The patient-centred multi-dimensional approach to COPD management ${ }^{22}$ [reproduced with permission]

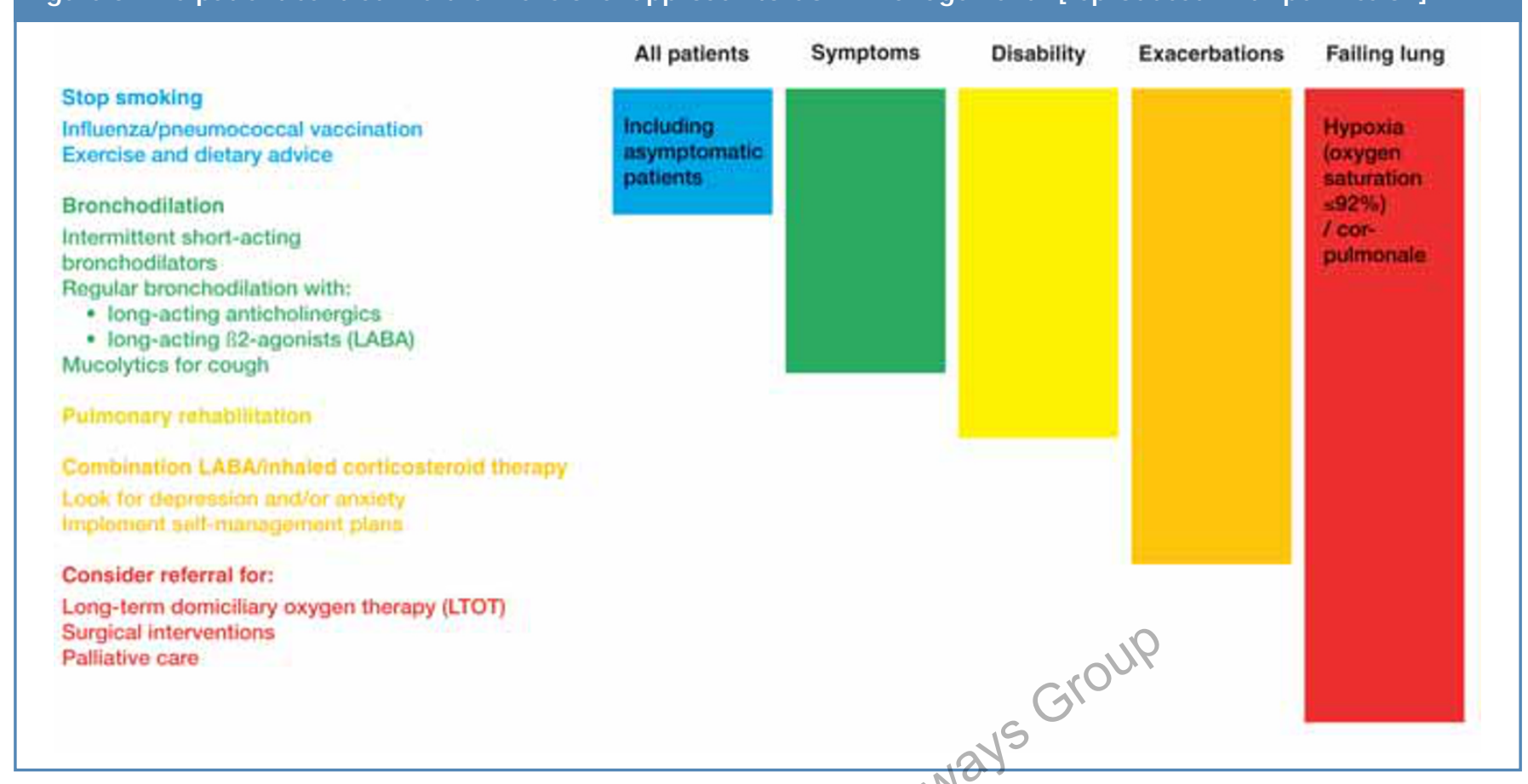

\section{Conflict of Interest declaration}

The author (KGJ) has acted as a consultant for, and spoken on behalf of, the following companies: AstraZeneca, Boehringer Ingelheim, GlaxoSmithKline, and Galen Pharmaceuticals.

\section{Acknowledgements}

This supplement was initiated, supported and funded by AstraZeneca UK Ltd. The author wishes to acknowledge the editorial support of Dorothy-Jean Grindlay, Senior Copywriter, Brand(x) Medical Education.

The author also gratefully acknowledges the support of the Department of Health and the GPIAG in giving permission for Figures 3,4 and 5 to be reproduced for this publication.

\section{Author declaration}

After initial concept discussions, AstraZeneca presented an outline to the author (KGJ). This was revised and subsequently re-written by the author. Dorothy-Jean Grindlay (DG) provided writing support as and when necessary, and support with reference checking and journal styling. The assistance of DG was funded by AstraZeneca. KGJ was involved with the initial concept of the paper, extensively involved with the writing and revisions of the paper, and retained full editorial control throughout the development of the manuscript.

\section{The "Unleash the life within" survey}

If you would like to receive a copy of the "Unleash the life within" survey, please send an e-mail with your contact details (name, position, surgery address and telephone number) to: azcst@apsgroup.co.uk

\section{References}

1. European Respiratory Society. European White Lung Book, 2003. Accessed from www.ersnet.org/ers/show/default.aspx?id_attach=6105 in September 2008.

2. The British Thoracic Society. The burden of lung disease. A statistics report from the British Thoracic Society 2006. Accessed from www.brit-thoracic.org.uk in September 2008.

3. Groenwegen KH, Schols AMWJ, Wouters EFM. Mortality and Mortality-Related Factors after Hospitalization for Acute Exacerbation of COPD. Chest 2003;124: 459-67.
4. Stang P, Lydick E, Silberman C, Kempel A, Keating ET. The Prevalence of COPD: Using smoking Rates to Estimate Disease Frequency in the General Population. Chest 2000;117(Suppl 2):354-9.

5. Healthcare Commission. Clearing the Air. A national study of Chronic Obstructive Pulmonary Disease, 2006. Accessed from www.healthcare commission.org.uk in September 2008.

6. The National Collaborating Centre for Chronic Conditions. Chronic Obstructive Pulmonary Disease - National clinical guideline on management of chronic obstructive pulmonary disease in adults in primary and secondary care. Thorax 2004;59(Suppl 1):1-232.

7. On the state of the public health: Annual report of the Chief Medical Officer 2004. Accessed from http://www.dh.gov.uk/en/Publicationsandstatistics/ Publications/AnnualReports/Browsable/DH_5323029 in September 2008.

8. 'Unleash the life within ...' a patient's perspective of living with Chronic Obstructive Pulmonary Disease (COPD) Survey. Sponsored by AstraZeneca UK Ltd.

9. Data on file, SYM/056/May 2008.

10. British Lung Foundation. Invisible Lives. Chronic Obstructive Pulmonary Disease (COPD) - finding the missing millions. Accessed from www.lunguk.org in September 2008.

11. Development of the National Services Framework. Accessed from http://www.dh.gov.uk/en/Healthcare/NationalServiceFrameworks/COPD/DH_O 85153 in September 2008.

12. NSF methodology and COPD NSF timescale. Accessed from http://www.dh.gov.uk/en/Healthcare/NationalServiceFrameworks/COPD/DH_0 85153 in September 2008.

13. Bednarek M, Gorecka D, Wielgomas J, et al. Smokers with airway obstruction are more likely to quit smoking. Thorax 2006;61:869-73.

14. White P. Spirometry screening for COPD: wishful thinking, not evidence. Thorax 2007;62:742-3.

15. Levy ML, Fletcher M, Price DB, Hausen T, Halbert RJ, Yawn BP. International Primary Care Respiratory Group (IPCRG) Guidelines: Diagnosis of respiratory diseases in primary care. Prim Care Resp J 2006;15:20-34. doi: 10.1016/j.pcrj. 2005.10.004

16. Gruffydd-Jones K. Screening for COPD ....and more...in primary care. 4th IPCRG 
world Conference Seville 2008 Communications book. Page 38.

17. NICE guidelines. Chronic obstructive pulmonary disease. Management of chronic obstructive pulmonary disease in adults in primary and secondary care; Guideline 12, February 2004. Accessed from www.nice.org.uk in September 2008.

18. Global Initiative for Chronic Obstructive Lung Disease. Global strategy for the diagnosis, management and prevention of chronic obstructive pulmonary disease. Updated 2007. Accessed from www.goldcopd.com in September 2008

19. Jones PW. Issues Concerning Health-Related Quality of Life in COPD. Chest 1995; 107(Suppl):187-93

20. Celli BR, Cote CG, Marin JM, et al. The Body-Mass Index, Airflow Obstruction,
Dyspnea, and Exercise Capacity Index in Chronic Obstructive Pulmonary Disease. N Engl J Med 2004;350(10):1005-12.

21. Jones R, Chavannes N, Kida K, Donaldson G, Hyland M, Price D. The DOSE index predicts quality of life, healthcare consumption and mortality. ERS annual conference 2007; Abstract 1602

22. General Practice Airways Group. Diagnosis and management of chronic obstructive pulmonary disease. A guide for those working in primary care, 2007. Accessed from www.gpiag.org in September 2008.

23. Jones R, Hyland M, Harding S, Price D. The derivation of a new index of severity for COPD patients, the DOSE index: MRC dyspnea scale, airflow obstruction, smoking status and exacerbations. ERS annual conference 2007; Abstract 1601. 